\title{
Classificação dos criminosos
}

\author{
H. Veiga de Carvalho \\ Livre docente de Medicina Legal
}

1 - A razão de ser da classificação dos criminosios ressalta da utilidade que toda e qualquer classificação apresenta dentro do ramo científico em que se formula. Como, para classificar, é mister estudar e conhecer profundamente o objecto dessa classificação, desde logo sobreleva a importância deste objectivo pela obrigatoriedade que contém de exigir o melhor conhecimento da cousa estudada. A classificação dos criminosos será o ápice de toda uma análise criminológica, tendente a ordenar, dentro de fórmulas simples, compreensíveis e gerais, aquelas pessoas que, mesmo na complexidade do seu feitio de indivíduos, venham a oferecer características globais que os aproximem coordenadamente de outros seres semelhantes.

É evidente que, para preencher esta qualidode de representar a síntese de um estudo criminológico, a classificação adoptada terá que demandar do classificador um estudo completo, profundo e percuciente da pessoa que delinquiu. IClassificações que não estejam jungidas tão intımamente a esta exigência, não podem preencher a finalidade última e útil de classificar.

2 - Em 1938, no Congresso Internacional de Criminologia, reunido em Roma, Manassero demonstrou que uma classificação dos delinquentes, para ser precisa e completa necessitaria de preencher os seguintes itens: $1 .^{\circ}$ ) 
ser genética, causal e não descritiva: $2^{\circ}$ ) ter como método de estudo a personalidade do delinquente; $3 .^{\circ}$ ) ser fundada sobre prostulados científicos e $4^{\circ}$ ) proporcionar critérios orientadores sobre a perigosidade e a emendabilidade.

Tenho para mim, que os 4 itens formulados lùcidamente por Manassero estão preenchidos pela classificação dos criminosos que tive a oportunidade de formular há 3 lustros atrás. E' bem verdade o que disse Afrânio Peixoto, citando Boucher: "terminados seus estudos, os retóricos fazem uma tragédia, como os alienistas uma classificação. Os criminalistas não são diferentes. ." Mas esta advertência não me tira o ânimo de continuar defendendo a classificação que propuz e que hoje vai sendo adoptada nalguns centros civilizados do mundo, assim como na própria terra do profeta, o que é de admirar.

3 - Alguns críticos dizem ser tarefa impossível uma classificação dos criminossos. E aparentemente têm razão porque é bem conhecida a dificuldade do estabelecimento de um conceito do que seja crime e do que seja criminoso. E lembram que é relativamente fácil encontrar bases para uma classificação botânica ou minerológica: há elementos conhecidos, mais ou menos fixos, amplamente favorecedores de critérios para classificação; ao passo que, para os criminosos, dada a complexidade do feitio de cada um, tal não seria possivel.

Não cabe razão a esta crítica. É apenas mais difícil classificar os criminosos. Para classificá-los, é mister estudo mais profundo e dilatado do que para classificar uma folha vegetal. Tudo isso é óbvio, mas tem sido esquecido. Até onde possa colher a crítica, ela se amolda àquelas classificações que usam uma terminologia assaz ambígua e referente apenas à aparência exterior da personalidade delinquente, como, por exemplo, dizer os criminosos "profissionais", "habituais", etc., porque assim pareçam ser. $O$ individuo reitera na acção 
criminosa, assemelhando-se a um "profissional" ou a um "habitual"? - receberá, desde logo, essa desinência, sem preocupações mais aprofundadas sobre os motivos, a personalidade, as influências, o grau ético do seu arbítrio, etc.. É claro que caberão comentários severos a essa maneira de classificação. E assim se repetirá para todas aquelas orientações de nomenclatura que se apoiem em visões parciais da personalidade dos criminosos, denominando-os, vez por vez, de violentos, sanguinários, anómalos cívicos ou morais, deficientes glandulares, etc., etc..

4 - Insistern, ainda, os que acreditam impossível classificar os criminosos, em lembrar que se trata de indivíduos. Esta crítica tem menos base: não há na Natureza nada criado perfeitamente idêntico ao seu semelhante; qualquer folha difere de todas as demais folhas da mesma planta; não há dois besouros iguais; diferenciam-se entre si todos os cristais de qualquer outra ou da mesma categoria. Claro que os criminosos são individuos diferentes entre si e de todos os mais. Mas não será, este, empecilho de monta para tornar inviável a trilha classificadora. Depende, isto sim, do critério adoptado para se classificar. E relembro os itens fundamentais formulados por Manassero e tomados zelosamente em conta ao formular as bases da classificação que tive a oportunidade de propor.

Esta classificação apresenta 5 grupos assim discriminados:

$$
\begin{aligned}
& 1 .^{\circ} \text { - Mesocriminoso (puro) } \\
& 2 .^{\circ} \text { - Mesocriminoso preponderante } \\
& 3 .^{\circ} \text { - Mesobiocriminoso } \\
& 4 .^{\circ} \text { - Biocriminoso preponderante } \\
& 5 .^{\circ} \text { - Biocriminoso (puro) }
\end{aligned}
$$

5 - Desde logo se verifica, pela simples prolacão dos 5 grupos fundamentais apresentados, que essa classificação 
se apoia nos factores únicos até hoje identificados, desde Ferri, e sine qua non, para que se fale em delinquência verdadeira. Sim, porque desde aquele autor se admite que, para falar em crime e em criminoso, é mister, no mesmo indivíduo, se casem os factores do ambiente, externos, exógenos, ou mesológicos, com os factores individuais, endógenos, internos ou biológicos. Não devemos deixar de repisar que estes são os elementos de estudo criminológico pròpriamente dito do delinquente. Transcendem a este campo de pesquisa os factores de ordem mais elevada, quais sejam os que entendem com o arbítrio, com a voluntariedade, com a responsabilidade do agente.

Mas, no terra-a-terra em que trabalha a Criminologia, são aqueles dois os factores que estão em jogo para se poder falar em criminoso.

6 - Por estas singelas palavras, desde logo se chega à conclusã̀o de que o primeiro e o último grupos enunciados se referem a pseudocriminosos, isto é, a pessoas que agiram anti-socialmente, mas que não podem ser criminosos porque, na génese de seu delito, entrou em acção tão sòmente o ambiente em que viveu essa pessoa ou os desvios patológicos a que esteve ela submetida; em ambos os casos, fica fora da sua responsabilidade a referida acção praticada. Só são verdadeiros criminosos os que apresentaram a associação de ambos os factores já conhecidos.

7 - Convém, neste passo, lembrar que a velha pendência entre a Escola Sociológica e a Escola Antropológica estrita em Criminologia, pretendendo exclusivismo ou preponderância etiológica dos factores mesológicos ou dos factores biológicos, não tem razão de ser. Caso por caso, haverá a prevalência deste ou daquele factor e, num apreciável número de eventos, a junção dos dois factores se fez sem predomínio de qualquer deles. Por 
essa mesma razão incluiram-se três grupos que reconhecem as preponderâncias respectivas do factor mesológico (no segundo) ou de factor biológico (no quarto), ou a inexistência ou incapacidade de aferir grau de preponderância, no grupo médio (terceiro).

Para a avaliação dos factores criminógenos e seu respectivo grau de predomínio, se existe, é mister fazer-se então análise profunda e suficientemente ampla da personalidade do criminoso em estudo. Costumo aconselhar a realização de sete grupos de exames, assim discriminados: Somático, Funcional, Psíquico, Psicológico, Social, Moral e Histórico ou Circunstancial. Cada grupo de exames deve ir tão longe quanto seja necessário e quanto o permitam as técnicas adequadas. Todos esses grupos de exames se podem compendiar com a desinência genérica de Criminografia - a descrição dos vários aspectos pelos quais pode ser observada a evolução e o comportamento da personalidade humana. Realizados esses exames, após cada grupo deles, chega-se a uma conclusão e a uma classificação referente aos diversos tipos morfofísio-psicológicos, morais e circunstanciais. Essa classificação, ou melhor, o resultado final de cada uma dessas vias de análise, vai permitir, conjugada com todas as demais classificações obtidas, justamente verificar se houve associação de factores criminógenos (quando é possível, então, falar-se em criminoso) ou o exclusivismo de um só factor, no caso dos pseudocriminosos. Sopesados todos esses elementos de estudo, estamos aptos para realizar a classificação estiológica dos criminosos, segundo acima se referiu. É clara, é mais que evidente, a necessidade de realizar um estudo minuciosíssimo do homem. que agiu anti-socialmente. Mas os benefícios que desse estudo se podem colher, pagam com largos juros o preço do trabalho realizado na análise criminológica. Numa: palavra, o que se deve fazer é uma pré-classificação do indivíduo em estudo, em cada uma das vias de acesso a 
análise da sua personalidade para, depois disso, compor-se a síntese criminológica da sua personalidade, que se há de exprimir nesta fórmula natural, etiológica e, por assim dizer, automática dos criminosos. Há pois, que estabelecer essa série de pré-classificaçōes, umas referentes ao soma, outras à função, outras à mente, ao lado das demais que dirão respeito ao complexo moral e social. Desta maneira, estabelecer-se-á, prèviamente à classificação criminal - a qual, insista-se, è a última a ser determinada - uma série de pré-classificações como, verbi gratia, individuo picnico (quanto ao soma), hipertireoideu (funcional), ciclóide (psíquico), extrovertido (psicológico), sintónico (social), moral, imoral ou amoral, e com esta ou aquela evolução social, educativa e de instrução. Somadas todas as informações em que se condensam os estudos preliminares - do antropometrista, do fisiólogo, do psiquiatra, etc. - e que deverão ser tantos quantos possam caber dentro das possibilidades e das necessidade 3 do serviço de que fazem parte, enfeixadas estas várias pré-classificações, poder-se-á ajuizar da classificação final que jogará, então, com elementos suficientes para poder alcançar a dosagem relativa da influência dos dois factores criminógenos sobre o delinquente estudado.

8 - Vê-se, desta maneira, que a classificação dos criminosos há de ser sintética na sua definição final; mas essa síntese só pode ser atingida, de maneira idónea, se se apoiar numa análise rebuscadamente minuciosa e exaustiva da personalidade do homem estudado. É por esta razão que a classificação etiológica dos criminosos, acima proposta, ainda quando tenha muito do ovo de Colombo, tem fundamento sólido e desenvolve-se dentro de um plano rigorosamente cientifico e perfeitamente lógico. Não assim outras clasificações, que pretendem o impossível, de partir de grupos gerais para se subdividirem em ramos e ramúsculos analíticos que deveriam, para abranger todas as 
possibilidades, de descer até a desinência de cada: uma das unidades do agregado social - o que é evidente utopia. Eis porque sempre defendi o critério sintético das classificações de criminosos, quando essa sintese dos grupos finais ressuma das rajzes que foram buscar, para cada distrito da personalidade humana, a seiva necessária para alimentar as conclusões derradeiras.

9 - Não cabe, neste breve resumo, o estudo aprofundado das várias classificações propostas, que já realizei num trabalho especializado - "Os Criminosos e suas Classes". Aí se recolheram explicitamente, em seus grupos, 53 classificações, citando-se, sem necessidade de minúcias, muitas outras mais, que seriam apenas repetições. Mas não posso deixar de assinalar um fenómeno que desde sempre chamou a minha atenção: o arquiclassificador, Mestre dos demais - ao qual se seguiram Lombroso, Ferri, Colajanni - o grande Gall, em 1825, propunha uma classuficação em dois grupos - 1. por paixão e 2. por instintos inatos; logo Lombroso aumentou o número para 4 , as suas bem conhecidas classes de criminosos - 1 . natos, 2. loucos, 3. por paixão, e 4. de ocasião; sucede-lhe Ferri, e, de 4, passa para 5, acrescentando o grupo dos criminosos que ele chama de hábito; vem depois Colajanni, e já não bastam 5, havendo necessidade de mais um, e lá vem o grupo dos criminosos políticos; e assim ir-se-ia somando a lista com criminosos religiosos, econômico-sociais, com repugnância ao trabalho metódico, "normais", e - que sei eu mais - tudo quanto a mente humana possa forjar, inventar, induzir, deduzir e por ai além.

10 - Não há que instar: estude-se o criminoso; para isso, adoptem-se todos os caminhos que a ciência e a arte reconheçam como idóneos; e, depois, construa-se a síntese, que só ela permite classificar os criminosos. E 
essa síntese levará, necessàriamente, à admissão das classes acima formuladas -- ainda que se possam dar aos bois outros nomes. A nomenclatura poderá variar; mas o caminho há de ser um só - analítico-sintético.

11 - Para que a classificação dos criminosos preencha realmente as suas funções, deve ela fornecer dados que nos permitam prever o comportamento futuro dos delinquentes, isto é, que nos concedam alguns dados em relação com a reincidência. $\dot{A}$ semelhança do que fez Silvio Marone, num seu laureado trabalho sobre a classificação dos criminosos, pode-se estabelecer o liame entre as classes de criminosos verdadeiros e sua respectiva reincidência dentro do esquema seguinte:

$\begin{array}{ll}\text { Mesocriminoso preponderante } & \text { Reincidente excepcional } \\ \text { Mesolbiocriminoso .... .. } & \text { Reincidente ocasional } \\ \text { Biocriminoso preponderante } & \text { Reincidente potencial. }\end{array}$

É tão clara a relação dessas possibilidades, que se podem dispensar perfeitamente quaisquer comentários.

12 - A este ponto, deve-se fazer uma referência à classificação penitenciária dos delinquentes. Tenho entendido, desde há muitos anos, que a existência de um problema particular, referente à classificação dos penitenciários - acreditada impossível por Émile Bertrand, Director da prisão de Louvain, e julgada perfeitamente viável, e dté imperativamente necessária, por Osvaldo Loudet- radica em que tal classificação deve servir ao ponto de vista administrativo das penitenciárias ou das casas de detenção. Atendida que seja a ponderável dificuldade que este problema administrativo acarrete, não há, contudo, como admitir uma dualidade de critérios, pois que critério seguro só existe um, e este é o que preside à citada classificação etiológica. 
Como insistentemente tenho repetido, o exame criminológico do delinquente deve ser prévio ao julgamento. Pela mesma razão, a classificação dos criminosos já deveria estar realizada antes que o réu fosse julgado. $\mathrm{E}$, assim, esta classificação, ou melhor, a análise criminológica que ela obriga a realizar, poderia indicar, no caso de condenação, para cada uma das classes de criminosos, já uma orientação "penal" adequada ao tipo de homem que esteve em jogo na acção anti-social produzida. Quero dizer com isto, que a classificação dos criminosos, não por ela, mas pelo exame a que ela força, poderia esclarecer o julgador e o aplicador da lei a orientar a terapêutica penitenciária no sentido mais útil para a recuperação social do agente criminoso. Neste sentido, permito-me sugerir o seguinte quadro que objectivaria, em largo debuxo, a matéria em estudo:

1. Biocriminoso (puro): pseudocrimi. noso:

2. Biocriminoso preponderante: de correção difícil.
3. Mesobiocriminoso: de correção possivel. tratamento médico psiquiátrico, temporário ou definitivo em réferência ao critério clínico, em Manicómio Judiciário;

tratamento em Colônias Disciplinares, em Casas de Custódia ou em Institutos de Trabalho, de reeducação ou de ensino profissional, com assistência médicopsiquiátrica e com eventual internação em Hospital Psiquiátrico, e segregação temporária ou definitiva. como medida de segurança;

tratamento no regime penal de Reformatório, progressivo e atendido médico e pedagògicamente; 
4. Mesocriminoso preponderante: de correcção esperada:

5. Mesocriminoso (pu ro) : pseudocrimi. noso: tratamento em colónias, com regime de trabalho adequado e com especial assistênicia sócio-pedagógica;

tratamento essencialmente pe'dagógico e de sintonização social.

13 - Éste quadro é apenas um esquema de orientação geral e que se subordinará ao problema particular da administração penitenciária. Realmente, o criminoso deve ser estudado e classificado, para que a prolação da Justiça seja mais esclarecida. Ao aplicar o tratamento "penal". decai o valor désta classificação: ou melhor, o indivíduo ficará mais à mercê das circunstâncias administrativas, das possibilidades maiores ou menores da organização penitenciária a que vai ser submetido, do que a mais finas excogitações que digam respeito à sua personalidade individualíssima.

Nos organismos penitenciários, o que se deve ter em mira mais directa e acuradamente, são as aptidões psicossomática, reveladas principalmente pela aferição psicotécnica, tendo por meta a melhor aplicação da laborterapia, ainda o melhor meio de reconquistar socialmente o criminoso. Isto está, aliás, determinado no novo Código Penal, em seu artigo 29 , $\& 1 .{ }^{\circ}$, para os sentenciados, e, no artigo 90, para os internados em virtude de medida de segurança. Insista-se em afirmar que, por fim, a classificação penitenciária dos criminsos está subordinada, de maneira assaz estrita, ao problema administrativo. Tais e tantas sejam as possibilidades e modalidades da laborterapia, outras tantas e tais serão as necessidades de classificação psicossomática e psicotécnica dos penitenciários, para melhor adaptação destes aos vários tipos de laborterapia possível naquele dado organismo penitenciário, Mas, reafirme-se que a própria e mesma classificação dos 
criminosos, já feita antes do julgamento (que assim seja!), dará os melhores subsídios para esta reclassificação laborterápica dos penitenciários.

14 - De tudo quanto disse até aqui, creio poder-se concluir que a classificação etiológica dos criminosos, acima formulada, corresponde plena e ortodoxamente às exigências apontadas ao Congresso de Roma, em 1938, pelo já citado Manassero. Assim, é uma classificação genética, causal e não meramente descritiva; ainda que a criminografia seja obrigatòriamente anterior à classificação sintética e final, esta é essencialmente etiológica, referindo-se, ou pretendendo fazê-lo, às causas conhecidas da delinquência. Ela tem como método de estudo a personalidade do criminosos, relacionando esta personalidade, entretanto, com o meio, com as circunstâncias, com osantecedentes que envolveram o acto anti-social; não é repisar que o método de estudo tem por meta exactamente revolver, até às suas mais finas investigações, a personalidade do agente anti-social.

A classificação funda-se, por isso mesmo, sobre postulados estritamente científicos; e vem de feição, agora, dar ênfase a que ela se prende mais à etiologia do que aos sintomas externos da acção criminosa; por outras palavras, ela foge ao uso de expressões como, por exemplo, delinquente habitual, ou ocasional, ou profissional, que são desinências de uma aparência exterior, meramente sintomática e que nunca explicaram a etiogenia do mal social verificado; já acima se lembrou o pouco valor de uma tal nomenclatura: o criminoso aparenta viver do seu crime? - è "profissional"; reincide com frequência? - é "habitual"; e assim por diante. No entanto, bem sabemos nós todos ser falaz o julgar pelas aparências. $O$ que importa é ir às razões do porquê desta manifestação externa da acção criminosa. E por isso, insisti e insistirei, em defender a classificação etiológica, como a única que 
se apoia em fundamentos científicos. E claro que o facto reincidência, que o comportamento aparentemente profissional ou habitual, tem de ser tomado em consideração; mas isto, não como qualificação final, mas apenas como uma das verificações que devem anteceder obrigatòriamente o enquadramento definitivo do grupo etiológico a que pertence o delinquente. Já se repisou suficientemente o tema.

Por fim, proporciona a classificação etiológica critérios orientadores sobre a perigosidade e a emendabilidade; viu-se, ind'agora, que há uma previsão possível da reincidência para os vários tipos de criminosos, como também a eles se pode ligar escorreitamente uma terapêutica "penal" perfeitamente adequada; a perigosidade, em si, também tem o seu diagnóstico possibilitado pela análise criminológica exigida pela classificação etiológica.

Aí estão, pois, em sucinta referência, apontadas as razões fundamentais que levaram ao ordenamento da classificação etiológica dos criminosos, as normas, a serem estabelecidas, e a sua defesa, cuja oportunidade se me ofereceu, neste momento, de realizar. 